Annales Geophysicae (2002) 20: 539-545 (c) European Geophysical Society 2002

\title{
Are variations in PMSE intensity affected by energetic particle precipitation?
}

\author{
V. Barabash ${ }^{1}$, S. Kirkwood ${ }^{1}$, and P. B. Chilson ${ }^{2}$ \\ ${ }^{1}$ Swedish Institute of Space Physics, Box 812, S-981-28 Kiruna, Sweden \\ ${ }^{2}$ NOAA Environmental Technology Laboratory and Cooperative Institute for Research in the Environmental Sciences \\ (CIRES), University of Colorado-NOAA, 325 Broadway, R/ET2, Boulder, CO 80305-3328, USA
}

Received: 23 April 2001 - Revised: 15 November 2001 - Accepted: 11 December 2001

\begin{abstract}
The correlation between variations in Polar Mesosphere Summer Echoes (PMSE) and variations in energetic particle precipitation is examined. PMSE were observed by the Esrange VHF MST Radar (ESRAD) at $67^{\circ} 53^{\prime} \mathrm{N}, 21^{\circ} 06^{\prime} \mathrm{E}$. The $30 \mathrm{MHz}$ riometer in Abisko $\left(68^{\circ} 24^{\prime} \mathrm{N}, 18^{\circ} 54^{\prime} \mathrm{E}\right)$ registered radio wave absorption caused by ionization changes in response to energetic particle precipitation. The relationship between the linear PMSE intensity and the square of absorption has been estimated using the Pearson linear correlation and the Spearman rank correlation. The mean diurnal variation of the square of absorption and the linear PMSE intensity are highly correlated. However, their day-to-day variations show significant correlation only during the late evening hours. The correlation in late evening does not exceed 0.6. This indicates that varying ionization cannot be considered as a primary source of varying PMSE, and the high correlation found when mean diurnal variations are compared is likely a by-product of daily variations caused by other factors.
\end{abstract}

Key words. Ionosphere (particle precipitation) Magnetospheric physics (energetic particles, precipitating) Meteorology and atmospheric dynamics (precipitation)

\section{Introduction}

Several recent studies of Polar Mesospheric Summer Echoes (PMSE) have addressed the possible influence of diurnal and semidiurnal tidal winds and temperature variations (e.g. Barabash et al., 1998; Klostermeyer, 1999). However, the situation becomes more complicated when the echoes' variability could be modified by extra ionization, added by precipitating energetic electrons from the magnetosphere or highenergy particles from the Sun. A number of investigations have been made on the possible relationship between PMSE and "absorption" registered by a riometer (e.g. Kirkwood et al., 1995; Klostermeyer, 1999; Bremer et al., 2000).

Correspondence to: S. Kirkwood (sheila.kirkwood@irf.se)
A riometer (Relative Ionospheric Opacity meter) measures the absorption of radio noise from the stars ("cosmic noise") in the ionosphere. Riometers usually operate at frequencies between $25 \mathrm{MHz}$ and $50 \mathrm{MHz}$, where radio waves are absorbed when there are significant numbers of free electrons between 60 and $110 \mathrm{~km}$ altitudes. They make continuous observations of the noise level and thus are used to observe decreases in the noise relative to the quiet day level, when highenergy particles precipitate and cause increased ionization.

Czechowsky (1989) found a weak positive correlation between 30 min mean average values of PMSE signal-tonoise ratio (SNR) and absorption during a period of $50 \mathrm{~h}$ in June 1984. This was interpreted as an indication of a nondominant influence of energetic particles on the strength and occurrence of the PMSE. Kirkwood et al. (1995) examined the occurrence of PMSE at $46.9 \mathrm{MHz}$ and $224 \mathrm{MHz}$ and energetic particle precipitation during a period of solar maximum, July-August 1991, when the solar produced ionization was substantially increased in the upper atmosphere. No statistical correlation was found using 1-h binned data, except for a few individual events for PMSE detected at $224 \mathrm{MHz}$ and riometer absorption at 30/38 MHz. Klostermeyer (1999) and Bremer (2000) have investigated PMSE variations during periods of low solar activity. Klostermeyer (1999) analysed the daily variation of radar reflectivity and the square of absorption with reference to a two-ion ice particle model. A strong correlation was reported for evening and morning events. However, it was noted that this fact might not be valid during strong absorption events, since the model assumption that the electron concentration is less than the ice particle concentration, is satisfied only during low ionization conditions. Bremer (2000) calculated the correlation coefficient for SNR and riometer absorption for morning hours using data averages over time periods during June and July in the years 1994 and 1997. These correlation coefficients did not exceed 0.37 .

This study presents a comparison of PMSE detected at $52 \mathrm{MHz}$ and riometer absorption at $30 \mathrm{MHz}$. Correlation coefficients are computed both for the mean diurnal variation 


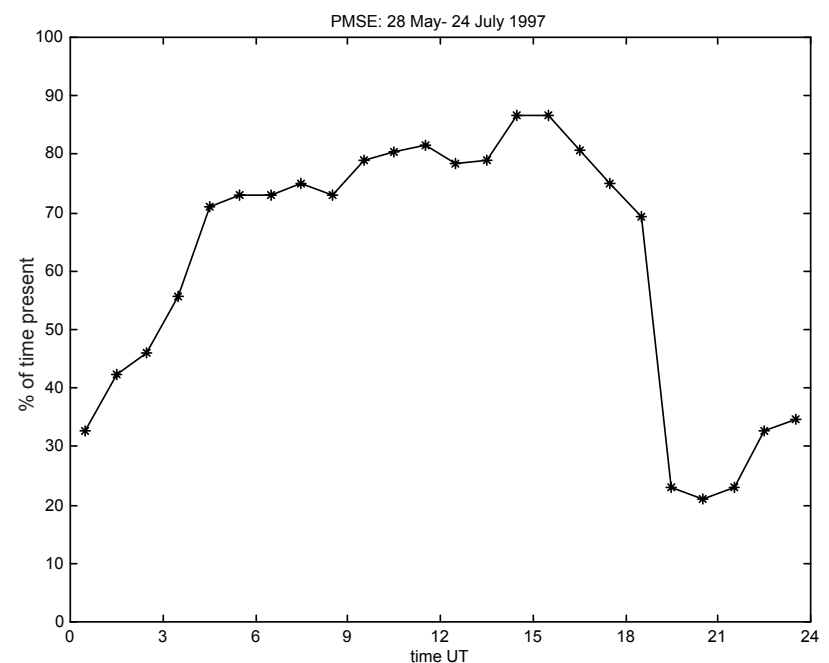

Fig. 1. Occurrence rate of PMSE during the period 28 May-24 July 1997 as a function of time of day.

and for the day-to-day variation (1-min time intervals). The period of study is the summer of 1997, during low solar activity.

\section{MST radar data}

During the summer of 1997, the MST radar (ESRAD) located at ESRANGE $\left(67^{\circ} 53^{\prime} \mathrm{N}, 21^{\circ} 06^{\prime} \mathrm{E}\right)$ in northern Sweden made continuous measurements of PMSE. ESRAD operates at $52 \mathrm{MHz}$ with $72 \mathrm{~kW}$ peak power and a maximum duty cycle of $5 \%$. The antenna consists of a $12 \times 12$ array of five-element Yagis with a $0.7 \lambda$ spacing. During the PMSE measurements, the radar beam was directed vertically and a 16-bit complementary code, having a Baud length of $1 \mu \mathrm{s}$, was used. This corresponds to a height resolution of $150 \mathrm{~m}$. The sampling frequency was set at $1450 \mathrm{~Hz}$. The local solar time at the radar site is 84 min later than UT.

In a separate study by Kirkwood et al. (1998) using ESRAD, it was shown that the prevalence of PMSE reached almost saturation ( $24 \mathrm{~h}$ present) during the period between 28 May and 24 July 1997. This period was also characterized by the lowest mesospheric temperatures and a stable westward wind pattern. Since the seasonal variation of PMSE was minimum during this period, it has been chosen particularly for the present study.

Echoes have been judged to be present if the signal-tonoise ratio (SNR) exceeded $-10 \mathrm{~dB}$. SNR values exceeding $50 \mathrm{~dB}$ have been excluded, since they represent technical limits. The radar data have been median filtered with a time resolution of $15 \mathrm{~min}$ and a height resolution of $900 \mathrm{~m}$. Averaging of the observations yields diurnal variations of the occurrence rate with a pronounced minimum at 19:00-22:00 UT (Fig. 1). For the remainder of the analysis, only the maximum values of SNR in the height range of $80-90 \mathrm{~km}$ for each sampling time are considered.

\section{Riometer data}

During the propagation of radio waves in an ionized medium, part of the wave energy is deposited in the forced oscillatory motions of the free electrons. This energy is re-radiated unless the electrons collide with the heavier ions, neutral atoms and molecules of the gas. The energy is thus absorbed from the wave. The integrated radio-wave absorption (nondeviative), A, along the given path has a form (e.g. Hargreaves, 1992):

$A=\frac{q^{2}}{2 \varepsilon m c} \int \frac{N v}{\left(\omega \pm \omega_{L}\right)^{2}+v^{2}} d s$,

where $\varepsilon$ and $c$ are the permittivity and speed of light in free space, respectively, $q$ and $m$ are the electron charge and mass. $N$ and $v$ are the local electron density and collision frequency values, $\omega_{L}=\omega_{c} \cos \theta$ is the longitudinal component of the electron gyro frequency $\omega_{c}, \omega$ is the angular frequency of the wave propagation at an angle $\theta$ with the geomagnetic field along the path $s$. The positive and negative signs in the denominator refer to ordinary and extraordinary waves. In the D-region $(60-90 \mathrm{~km})$, the collision frequency is determined mainly by electron-neutral interactions. Enhancements in the electron densities $N$, as well as increases in the collision frequencies $v$, may cause enhanced absorption. Thus, processes which increase the ionization densities in regions where the collision frequencies are significant (e.g. energetic particle precipitation in the D-region) or processes that increase the collision frequencies where the electron densities are large (e.g. electron temperature increases in the E-region, 90-140 km) may cause radio-wave absorption events.

Continuous measurements of absorption (our proxy for energetic particle precipitation and ionization) in this study were provided by the La Jolla fast-response solid-state riometer observing at $30 \mathrm{MHz}$, which is located in Abisko $\left(68^{\circ} 24^{\prime} \mathrm{N}, 18^{\circ} 54^{\prime} \mathrm{E}\right)$. The absorption has been calculated according to:

$A=10 \log _{10}\left(\frac{P_{0}}{P}\right)$,

where $A(\mathrm{~dB})$ is the cosmic noise absorption in decibels, $P_{0}$ is the power output in the absence of the ionosphere and $P$ is the signal power output of the riometer. $P_{0}$ depends on the direction of the antenna relative to the stars and it changes in a cyclic manner due to the rotation of the Earth (with a period corresponding to the sidereal day). It should also be noted that this operating frequency, $30 \mathrm{MHz}$, has been found to be the best compromise between the ionospheric layer critical frequency and the ability to avoid interference from the crowded short-wave bands (Hunsucker, 1991).

The occurrence rate of different absorption levels is presented in Fig. 2. The data have been median filtered with a time resolution of $15 \mathrm{~min}$. There is a clear minimum at 18:00-22:00 UT in absorption in the range of 0.5-1 dB. This is expected as a consequence of electron drift in the magnetosphere. An increase in absorption occurs in the late 


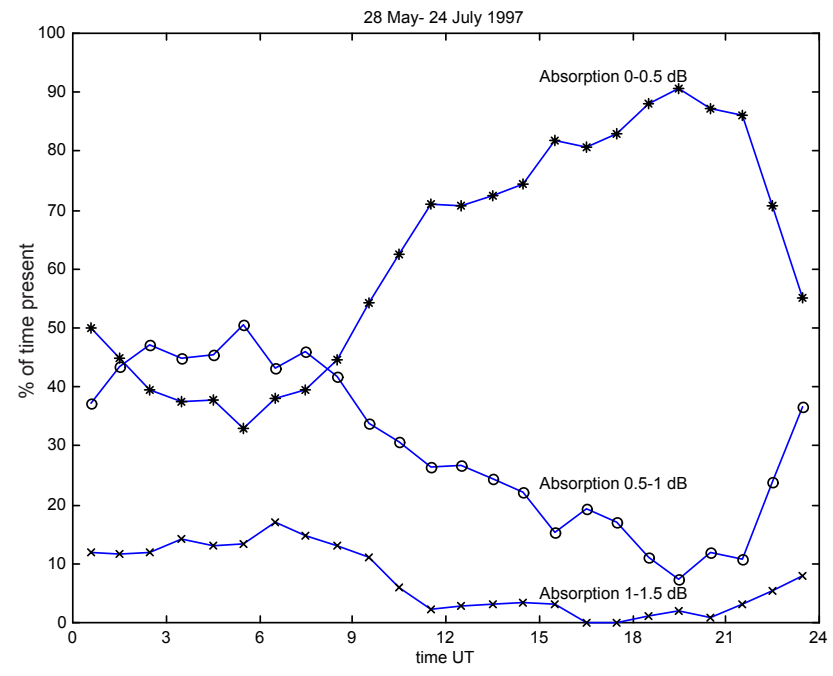

Fig. 2. Occurrence rate of different absorption levels during the period 28 May-24 July 1997 as a function of time of day.

evening and morning hours which is mainly due to the auroral substorm activity. The latter is considered to be related to large-scale instabilities in the tail region of the magnetosphere (Akasofu, 1977; Kan et al., 1991; Rostoker, 1996). (The daily variation of low absorption is opposite to that for high absorption, since the sum of all curves together must be $100 \%)$.

\section{Comparison of riometer data with MST radar data}

The absorption depends on the electron collision frequency and the electron density, both of which vary with altitude. However, it was shown by Friedrich and Torkar (1983, 1995) that the particle-generated electron concentration in the Dregion is linearly correlated with the absorption measured in decibels. Using the two-ion ice particle model, Klostermeyer (1999) suggested a possible relationship between the radar reflectivity, $\sigma$, and the absorption of the cosmic noise caused by the particle generated electrons, $L$ :

$\sigma=(1+\alpha \Delta T)\left[\beta\left(C h_{\chi}\right)^{-1.4}+\gamma L^{2}\right]$,

where $\chi$ is the Sun's zenith angle, $C h_{\chi}$ is the Chapman function, $\alpha=\partial \ln a / \partial T$ at $T=T_{0}$. Furthermore

$a=b \exp \left(2 \int_{z_{0}}^{z} \frac{d z}{h}\right) / h^{2}$,

where $h$ is a scale height, $b$ is a factor depending on the radar Bragg wave number, kinematic viscosity, energy dissipation rate of the neutral gas, Brunt-Väisäillä frequency and the Schmidt number of the electron gas. $\beta$ and $\gamma$ depend on $a\left(T_{0}\right)$ and on the proportionality factors in the linear relation between $n_{0}^{2}$, the electron concentration, $\left(C h_{\chi}\right)^{-1.4}$ and $L^{2}$. Using the model predictions for the diurnal and semidiurnal tides at a height of $85 \mathrm{~km}$, Klostermeyer (1999) found

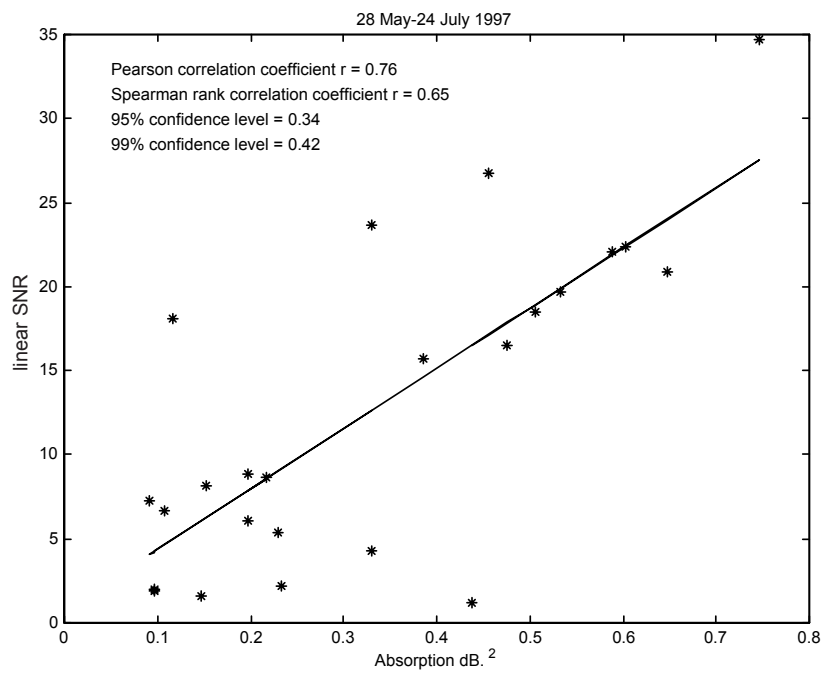

Fig. 3. Scatter plot of linear signal-to-noise ratio versus the square of absorption for the mean daily variations for the period 28 May24 July 1997. Data have been averaged over the entire interval, binned into 1-h UT time intervals.

the term $\alpha \Delta T$ to be less than 0.1 and, therefore, negligible. However, since the term $\alpha \Delta T$ might vary for different heights and time periods, the above-mentioned assumption is likely to be considered only as a rough approximation for our study. According to electron density profiles from the EISCAT Tromsö radar (Friedrich and Kirkwood, 2000), the term $\beta\left(C h_{\chi}\right)^{-1.4}$, where $\beta=1.81$ (Klostermeyer, 1999), is also negligible for solar minima, i.e. for the year 1997. Therefore, the radar reflectivity becomes a linear function of the square of absorption.

Since the radar reflectivity has been determined as a ratio of the backscattered signal power to the diurnal mean of the noise (Klostermeyer, 1999), an SNR should be considered. In the present study, the relationship between the linear SNR and the square of absorption has been estimated by two methods: by Pearson or linear correlation and by the Spearman rank correlation (Wilks, 1995). One can view the Pearson correlation as the ratio of the sample covariance of two variables to the product of the two standard deviations:

$r_{x y}=\frac{\operatorname{cov}(x, y)}{s_{x} s_{y}}$

This correlation has two limitations: it is neither robust nor resistant. It is not robust because strong yet nonlinear relationships between the two variables may not be recognised. It is not resistant since it can be extremely sensitive to one or a few outlying point pairs. A robust and resistant alternative to the Pearson correlation is the Spearman rank correlation, which is the Pearson correlation coefficient computed using the ranks of the data. Thus, while the Pearson correlation coefficient reflects the strength of linear relationships, the Spearman rank correlation reflects the strength of monotonic relationships. An approximate formula for predicting 

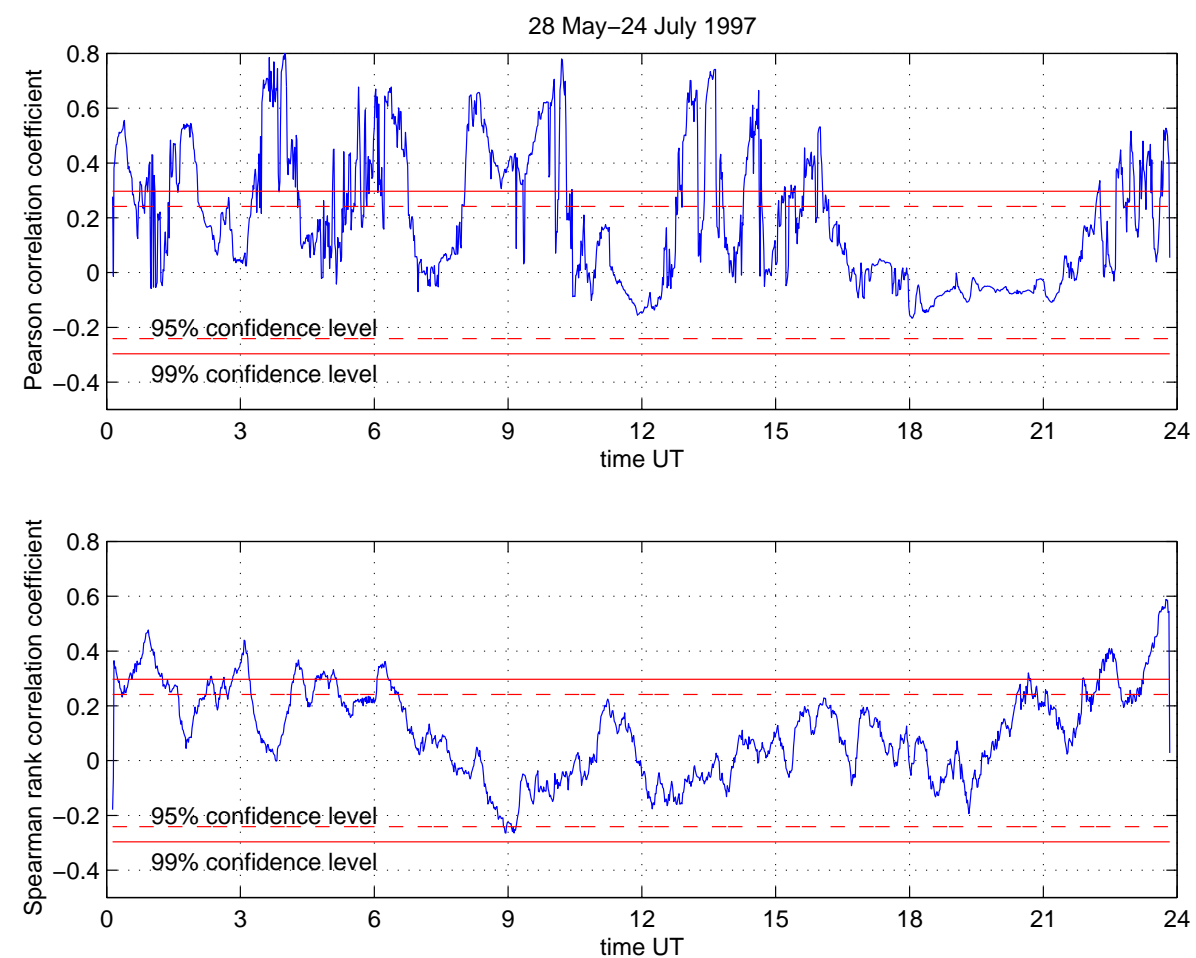

Fig. 4. Pearson correlation coefficient and Spearman rank correlation coefficient computed for day-to-day variations for each 1-min UT time interval over the day. Calculations are based on the square of absorption and linear signal-to-noise ratio data taken over all the observation days for each particular time interval.

the $95 \%$ confidence level is given by (Bloomfield, 1975; Julian, 1975; Franke et al., 1992):

$S_{0.95}=\left(1-(0.05)^{\frac{1}{N-1}}\right)^{1 / 2}$,

where $N$ is the number of independent data samples in the time series.

Figure 3 illustrates the correlation between the mean daily variation of the square of absorption and the linear SNR, averaged over the period 28 May - 24 July 1997, for each hour of the day. Pearson and Spearman correlation coefficients, and $95 \%$ and $99 \%$ confidence levels, are indicated on the figure ( $N$ is the total number of points as given on Fig. 3). Both Pearson and Spearman coefficients are rather high, i.e. 0.76 and 0.65 , respectively, and well above the $99 \%$ confidence level. Using the more robust Spearman rank coefficient this indicates that $43 \%$ of the daily variation in PMSE intensity (SNR) can be statistically explained by the daily variation in absorption.

However, the situation changes completely if we instead correlate the day-to-day variation of PMSE and absorption, separately for each minute of the day, i.e. we take a time series consisting of the average PMSE SNR between 00:00 and 00:01 UT on each day between 28 May and 24 July 1997, and test the correlation with the absorption at the same times. This is repeated for each minute of the day, and the results are shown in Fig. 4. It is clear that both the Spearman and
Pearson coefficients are below the $95 \%$ confidence level for most of the day. The Spearman rank coefficients are generally less than the Pearson coefficients, which is likely to be related to the statistical distribution of the data points: for example there are "outlier" pairs that bias the Pearson coefficients. The more robust Spearman coefficients indicate correlations exceeding the $95 \%$ confidence level only between about 20:00 UT and 06:00 UT, and then only during part of that time period. For the interval 20:00-06:00 UT, on average, the correlation coefficient is about 0.3 , i.e. less than $10 \%$ of the PMSE variation is correlated with variation in absorption.

To further test the possible correlations, we have also divided the data according to the absorption level. Correlation coefficients for different absorption levels are presented in Figs. 5 and 6. Figure 5 shows the results for low absorption, i.e. equal to or less than $1 \mathrm{~dB}^{2}$, and Fig. 6 shows the results for absorption above $1 \mathrm{~dB}^{2}$. In the latter case, there are no results for part of the day (10:00-22:00 UT) due to the rather low occurrence rates of higher absorption values. It is seen that the Spearman rank coefficients exceed 95\% confidence levels only between 20:00-24:00 UT (for low absorption levels) and their maximum values in this time interval are about 0.45 . This means that even during the time interval 20:00-24:00 UT, no more than 20\% of the day-to-day PMSE variation can be explained (statistically) by the variation in absorption. The correlation coefficients were also computed for absorption less than $0.5 \mathrm{~dB}$, but the results were not sig- 

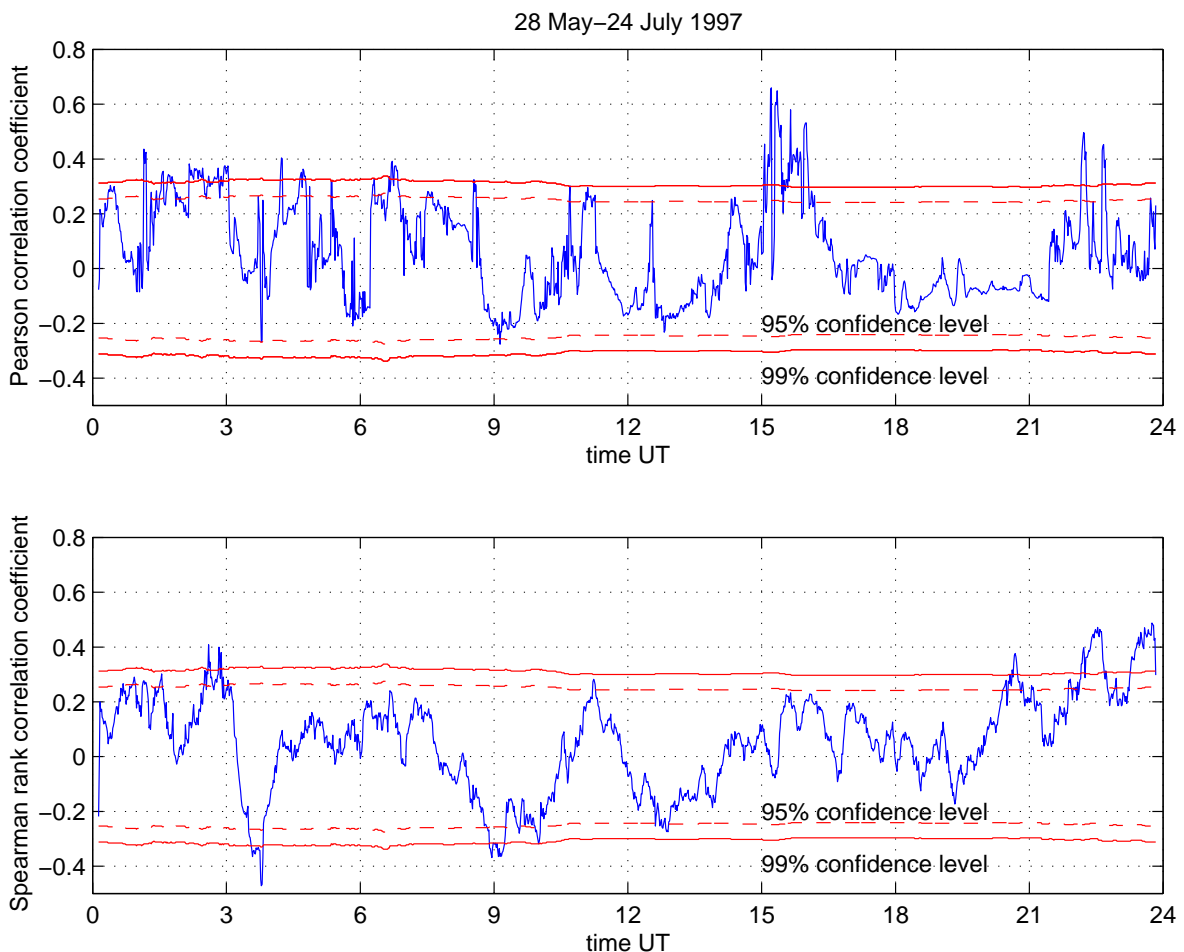

Fig. 5. Same as Fig. 4, except that only data for which the square of absorption was less than $1 \mathrm{~dB}^{2}$ were used when calculating the correlation coefficients.

nificantly different from Fig. 5 .

\section{Conclusion}

In the quiet D-region, the primary ions are typically $80 \%$ $\mathrm{NO}^{+}$and $20 \% \mathrm{O}_{2}^{+}$. $\mathrm{NO}^{+}$provides the primary source of electrons in the lower thermosphere and mesosphere, and attains a minimum value between 80 and $90 \mathrm{~km}$ height due to its photodissociation with the subsequent recombination with $\mathrm{N}^{4} \mathrm{~S}$. The depth of the minimum $\mathrm{NO}^{+}$concentration is determined by the equilibrium between photochemical loss and downward transport (Brasseur and Solomon, 1986). During particle precipitation events, the amounts of $\mathrm{NO}^{+}$and $\mathrm{O}_{2}^{+}$are increased, although $\mathrm{O}_{2}^{+}$increases most and becomes dominant. At low temperatures three-body clustering of $\mathrm{O}_{2}^{+}$ becomes important. First the ion $\mathrm{O}_{2}^{+}\left(\mathrm{H}_{2} \mathrm{O}\right)$ and then the ion $\mathrm{O}_{2}^{+}\left(\mathrm{H}_{2} \mathrm{O}\right)_{2}$ appear. A further addition of water leads to the conversion of $\mathrm{O}_{2}^{+}\left(\mathrm{H}_{2} \mathrm{O}\right)_{2}$ to $\mathrm{H}^{+}\left(\mathrm{H}_{2} \mathrm{O}\right)_{2}$, and then to higher hydrates (Wayne, 1991). Clusters with between 3 and 12 water molecules have been registered during the rocketborne mass spectrometric experiment in Kiruna (Kopp and Herrman, 1984). The rate of clustering is limited by a process the rate of which is proportional to the pressure squared and is thus highly altitude dependent. The direct hydration process involving $\mathrm{NO}^{+}$has been found to be much slower than for $\mathrm{O}_{2}^{+}$and extremely sensitive to temperature changes. Therefore, it seems that particle precipitation creates conditions more favorable for the water clusters to be formed. On the other hand, the recombination coefficients of water clusters with electrons are greater than those for $\mathrm{NO}^{+}$and $\mathrm{O}_{2}^{+}$. Therefore, it might be suggested that the water clusters are more easily destroyed during the intensive absorption event, which could decrease the expected positive correlation between the riometer absorption and SNR.

Another aspect of PMSE microphysics that should be mentioned is aerosol charge. The charge of an ice aerosol depends on the balance between the ion and electron content on its surface. Jensen and Thomas (1991) found a charge number of -1 for radii less than $10 \mathrm{~nm}$, and a linearly increasing charge with the aerosol size. Reid (1997) noted that this result will also depend on the ionization rate, and for a low ionization rate, all electrons and ions will be attached by aerosols, so that deep bite-outs will occur in electron and positive number density profiles. As the ionization rate increases with increased energetic particle precipitation, the ion-electron balance on the aerosols would be changed and thus an increased negative charge of the ice aerosol would be expected.

However, since the correlation between the linear signalto-noise ratio and absorption on a day-to-day basis is rather weak, the variations in ionization cannot be considered as a primary source of varying PMSE. The high correlation found when averages over several days are computed is not likely to be a sign of a causal connection between SNR and absorption, but rather a by-product of the fact that both absorption and PMSE have strong daily variations caused by other factors not considered in our analysis. One feature in the 

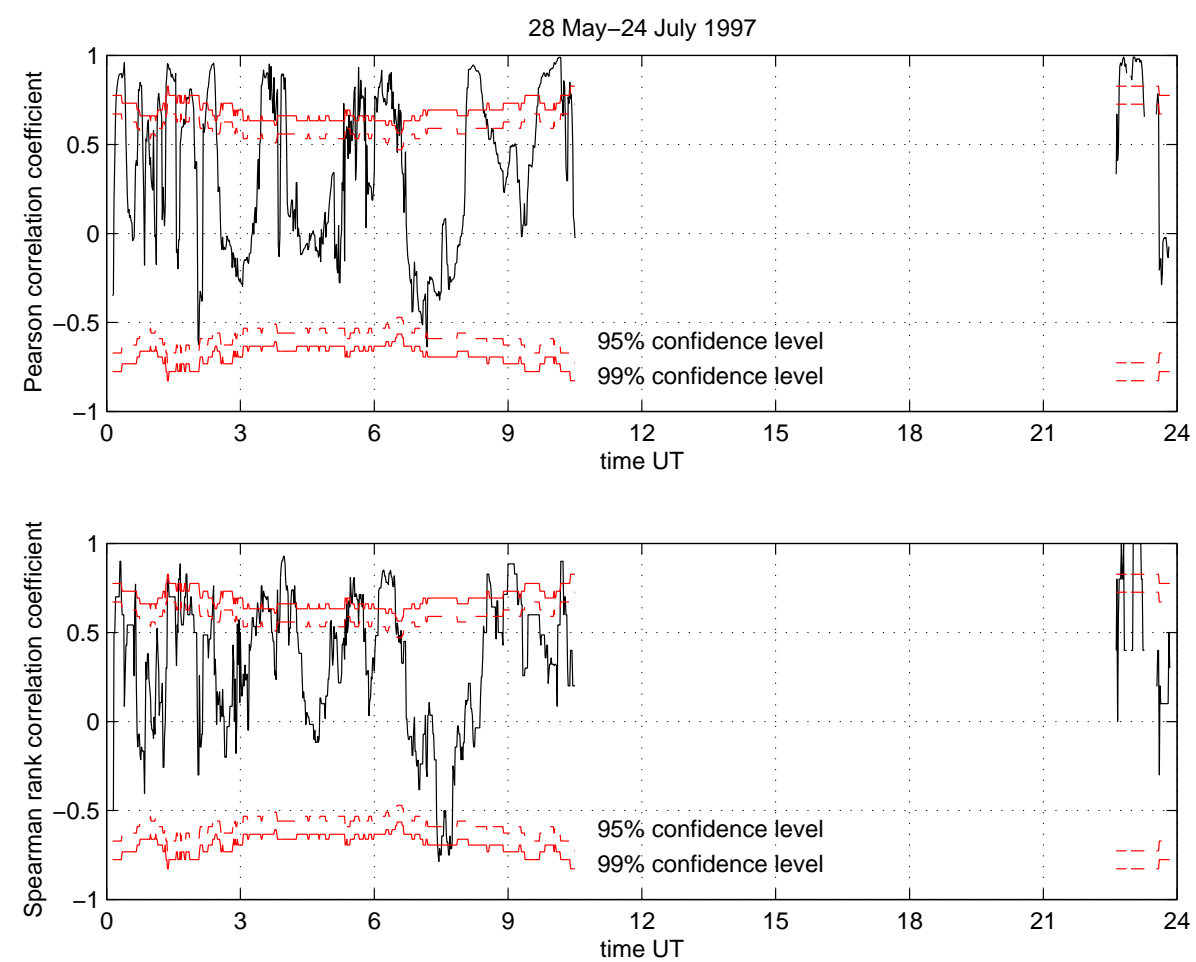

Fig. 6. Same as Fig. 3, except that the Pearson correlation coefficients and Spearman rank correlations coefficient were computed for 1-min intervals. Also, only data for which the square of absorption was greater than $1 \mathrm{~dB}^{2}$ were used when calculating the correlation coefficients.

daily variation which is of particular interest is the deep minimum in PMSE between 19:00 and 22:00 UT (see Fig. 1). It has been suggested, for example, by Klostermeyer (1999), that this is simply due to low levels of ionization, in turn due to the low solar elevation and the low levels of energetic particle precipitation. The timing of the minimum does not coincide with the lowest solar elevations, which occur at 22:40 UT (local solar midnight). Note that for the dates used there will still be some solar radiation reaching PMSE heights even at solar midnight. In any case, for the radar location in the auroral zone, energetic particles are generally a far greater source of ionization at these altitudes than is solar radiation. However, the analysis in Fig. 4 clearly shows that a lack of energetic particles cannot be the explanation for the PMSE minimum between 19:00-22:00 UT, both the Spearman and Pearson correlation coefficients are very small, less than 0.1 , and well below the $95 \%$ confidence level for almost all of the 19:00-22:00 UT interval, i.e. significant levels of ionization, enough to produce variations in the observed absorption exceeding $0.5 \mathrm{~dB} 10 \%$ of the time, are simply not correlated with any changes in PMSE intensity. Note that $0.5 \mathrm{~dB}$ absorption corresponds to about 5 times the normal, undisturbed ionization level produced between 80 and $90 \mathrm{~km}$ altitude at solar minimum by the midday Sun and at least 20 times that produced by the midnight Sun (Kirkwood and Collis, 1987; Kirkwood 1993).

The present analysis was completed for a period of solar minimum. Quite different results might be expected dur- ing solar maximum, because high solar activity levels are accompanied by increased Joule heating, injection of energetic particles and increased intensity of extreme ultraviolet and Lyman $\alpha$ radiation, which can influence the dynamics and chemistry of the upper atmosphere, in general, and the ionization of the PMSE region, in particular. Nevertheless, as the PMSE demonstrates the very same diurnal variation for solar maximum and solar minimum, it seems likely that some factor other than ionization, for example, temperature, is the most important cause of both daily and day-to-day variations in PMSE.

Acknowledgements. We thank Dr. J. Manninen from the Sodankylä Geophysical Observatory in Finland for providing the riometer data from Abisko.

Topical Editor D. Murtagh thanks T. A. Blix for his help in evaluating this paper.

\section{References}

Akasofu S.-I.: Physics of Magnetospheric Substorms, D. Reidel Publishing Company, Holland, 1977.

Barabash, V., Chilson, P., Kirkwood, S., Réchou, A., and Stebel, K.: Investigations of the possible relationship between PMSE and tides using a VHF MST radar, Geophys. Res. Lett. 25, $3297-$ 3300, 1998.

Bloomfield, P.: Fourier Analysis of Time Series: An Introduction; John Wiley, New York, 1975. 
Brasseur, G. and Solomon, S.: Aeronomy of the Middle Atmosphere, 2nd edition, D. Reidel Publishing Company, Holland, 1986.

Bremer, J., Hoffman P., and Hansen T. L.: Geomagnetic control of polar mesosphere summer echoes, Ann. Geophysicae, 18, 202208, 2000.

Czechowsky, P., Reid, I. M., Rüster, R., and Schmidt, G.: VHF radar echoes observed in the summer and polar winter mesosphere over Andoya, I. Geophys. Res., 94, 5199-5217, 1989.

Franke S. J., Röttger, J., LaHoz, C., and Liu, C. H.: Frequency domain interferometry of polar mesosphere summer echoes with the EISCAT VHF radar, Radio Science, 27(3), 417-428, 1992.

Friedrich, M. and Torkar, K. M.: High-latitude plasma densities and their relation to riometer absorption, J. Atmos. Terr. Phys., 45, 127-135, 1983.

Friedrich, M. and Torkar, K. M.: Typical behaviour of the high latitude lower ionosphere, Adv. Space Res., 16 (1), 73-81, 1995.

Friedrich, M. and Kirkwood, S.: The D-region background at high latitudes, Adv. Space Res., 25 (1), 15-23, 2000.

Hargreaves, J.: The Solar-Terrestrial Environment, Cambridge University Press, Cambridge, 1992.

Hunsucker R. D.: Radio techniques for probing the terrestrial ionosphere, Springer-Verlag Berlin Heidelberg, 1991.

Jensen, E. and Thomas, G. E.: Charging of mesospheric particles: implication of electron density and particle coagulation, J. Geophys. Res., 96 (18), 603-618, 1991.

Julian, P. R.: Comments on the determination of confidence levels of the coherence statistics, J. Atmos. Sci., 32, 836-837, 1975.
Kan, J., Potemra, T. A., Kokobun, S., and Iijima, T.: Magnetospheric Substorms, Geophysical Monograph, 64, American Geophysical Union, 1991.

Kirkwood, S.: Modelling the undisturbed high-latitude E-region, Adv. Space. Res. 13(3), 101-104, 1993.

Kirkwood, S. and Collis, P.: The high-latitude lower ionosphere observed by EISCAT, Adv. Space. Res. 7(6), 83-86, 1987.

Kirkwood, S., Cho, J., Hall, C. M., Hoppe, U.-P., Murtagh, D. P., Stegman, J., Swartz, W. E., van Eyken, A. P., Wannberg, G., and Witt, G.: A comparison of PMSE and other ground-based observations during the NLC-91 campaign, J. Atmos. Terr. Phys., 57, 35-44, 1995.

Kirkwood, S., Barabash, V., Chilson, P., Rechou, A., and Stebel, K.: The 1997 PMSE season - its relation to wind, temperature and water vapour, Geophys. Res. Lett., 25 (11), 1867-1870, 1998.

Klostermeyer, J.: On the diurnal variation of polar mesosphere summer echoes, Geophys. Res. Lett., 26 (21), 3301-3304, 1999.

Kopp, E. and Herrman, U.: Ion composition in the lower ionosphere, Ann. Geophysicae, 2 (83), 1984.

Reid, G. C.: On the influence of electrostatic charging on coagulation of dust and ice particles in the upper mesosphere, Geophys. Res. Lett., 24, 1095-1098, 1997.

Rostoker, G.: Phenomenology and physics of magnetospheric substorms, J. Geophys. Res. 101, 12 955, 1996.

Wayne, R.: Chemistry of Atmospheres, 2nd edition, Oxford University Press, Walton Street, Oxford, 1991.

Wilks, D. S.: Statistical Methods in the Atmospheric Sciences, Academic Press, San Diego, 1995. 